\title{
Governance of the Regulatory Decision Making Process
}

Second Annual Conference on the Future of Financial Regulation

London School of Economics

April 6-7 2006

Brian Quinn 


\section{Governance}

Governance is a late $20^{\text {th }}$ century/early $21^{\text {st }}$ century buzz-word. Its meaning has varied.

I will use it to mean, generally, the way in which things get done in financial regulation and supervision thus encompassing structure, decision making processes, resources and people.

I will look at how regulatory decisions are taken, and implemented, at national as well as international level. Attention tends to be concentrated on the latter; but the former is where things are actually done, for good or for ill.

\section{Independence}

Keeping the regulatory and supervisory authorities free from political and commercial interference is as important as in the case of the Central Bank. Governments all over the world take a close interest in financial intermediaries, because their operations are crucial to the economy and thus to political developments, to say nothing about Governments' electoral prospects. The urge to control their activities is never far away.

The involvement of privately owned commercial parties adds a dimension that is not present - or at least as directly - as in the case of monetary policy. Banks, securities firms and insurance companies have a stake in the specific form of regulatory and supervisory rules and decisions, so the incentive to influence these decisions is powerful. A financial company's business could be effectively destroyed, or at least seriously damaged, by an adverse decision.

Let's look at the risks arising, both in the case of Governments and in the case of financial intermediaries, in a little more detail. There are three distinct functions in the supervisory process: authorisation (or granting a license), supervision (monitoring compliance with regulations) and enforcement (the application of appropriate sanctions). Governments in some countries can and do interfere at all three stages. The telephone call might come from the Minister himself, demanding that a business acquaintance be granted a license; or it might come from a civil servant wondering why a firm line was not being taken with individuals whose behaviour was bringing the financial system into disrepute. In fact, it is not uncommon in some parts of the world for Governments to retain the power to issue and withdraw licenses and to leave the monitoring of compliance to the supervisory authority. This is a recipe for muddle, at best, and disaster, at worst.

The authority of the regulatory authority can also be compromised by other, more subtle, means. Appointing and dismissing senior officials at the discretion of the Government, controlling the annual budget of the regulatory authority and subjecting officials to legal action for negligence or incompetence are other methods of keeping control within the grasp of Government.

These are not fanciful examples. It is not uncommon in South America for supervisors to be charged with negligence in the performance of their duties, while acting in good faith; conviction can carry a prison sentence. The Deputy Governor of the Central Bank of Brazil formerly responsible for banking supervision is currently appealing against a six-year prison sentence for negligence in respect of a bank which failed.You can imagine how attractive her job will seem to other able people in this environment.

Of course legal and operational independence does not mean total discretion. The safeguards that apply in the case of monetary authorities apply equally in the area of regulation and supervision: transparency of operating procedures, fixed term appointments for heads of function, accountability to the legislature, publication of decisions, and due process under the law. Most supervisors I know 
welcome these limits on their powers as a price worth paying for independence of judgement and action.

Accountability can also be delivered, or fortified, through scrutiny by an independent body populated by individuals who have the necessary expertise not always evident in legislatures. The Board of Banking Supervision did this job during my time as banking supervisor. Such a model works only if the choice of members is itself free of Government or commercial influence; but the answer then lies in setting out clearly the powers of such a body and ensuring that its reputation is publicly on the line.

In the end, having a weak regulatory and supervisory body is self defeating. If the financial system is subject to political manipulation or corruption, failures or crises are inevitable, with sometimes huge damage to the economy. Countries which follow this course also suffer lasting reputational damage. This won't stop it happening, but just as the case for the independence of Central Banks has eventually been won, the same case must be pursued for regulators and supervisors.

\section{Regulatory Capture}

Returning to the commercial dimension of independence, how pervasive is the practice of "regulatory capture"? And how pernicious is it?

There is, to my mind, nothing very wrong with bringing pressure to bear on regulators with a view to protecting or advancing your own interests. The complexity of markets and the proliferation of products and services mean that almost every financial institution will be offering something it believes to be special - or at least profitable. They will also be anxious to ensure that they do not suffer a competitive disadvantage because of the specifications set by the regulators - the "level playing field" demand. Financial institutions are very adept at persuading others - and even themselves - that their product really is different and deserves to be treated as such.

Managing such pressures can be helped by following a consultative process that collects and presents the views of the interested parties. This process can be formal, as in the United States, where the regulatory authorities publish their proposals and allow a fixed period for representations; or informal, as in many European countries, where discussions between the authorities and representative bodies can take place without time limit. Members of the representative bodies watch one another like hawks to ensure that a kind of equality is preserved.

Do the larger institutions persuade or even bully the regulators into concessions that give them preference? Do the smaller institutions get pushed to one side in the crush to reach a decision on new regulations? I very much doubt it, on both questions, at least in my own experience. One of the first pieces of guidance given to a new supervisor is to look out for special pleading; and if the head of function stands behind his people - and I can think of no quicker way to lose the support and respect of your staff than to acquire a reputation for yielding to pressure - they will quickly develop their own resistance techniques.

The process of regulation does not, however, always take the form of set pieces. Questions and proposals about the implementation of regulations arise virtually daily. The evolution of financial products which aim to qualify as capital under the Capital Accord is a good case in point. At the Basle Committee, the first item on the agenda was to have a tour de table where we informed our colleagues about developments in, and challenges to, our regulatory and supervisory regimes. There was a genuine desire to help one another solve such problems and, anyway, a concession granted in one country would quickly be presented to supervisors in other countries; so there was a common interest. 
In general, the more developed the markets and the more diversified the participants, the less likely it is that large or powerful institutions will exercise undue influence on the regulatory and supervisory process. But this generalisation has to be qualified. Whether in the guise of national champions, or because certain institutions play a significant part in a market of special social or political importance, some financial institutions use that position to seek special treatment. This is not regulatory capture in the commonly understood sense, but it adulterates both of the aims of prudence and equality of treatment; and it certainly leads to horse trading.

During the discussions leading to the first Basle Capital Accord it became fairly clear that certain supervisory authorities were working to protect the interests of their own banks as a whole, sometimes on the bigger issues such as the definition of capital and sometimes on matters of detail, such as the weighting of a particular type of asset. I was troubled by this, since everyone else was then anxious not to have their own banks disadvantaged. There was a risk that the Accord would become an exercise in competitive devaluation, as it were. There was indeed a certain amount of horse trading, but the Secretariat, and some of the leading countries, ensured that it did not become excessive.

The important thing was to keep the objective of the exercise in mind and ensure the correct result as a whole was delivered. Sometimes the process became bogged down; and sometimes temporary compromises were struck. But this was done openly within the Basle Committee and not by backstairs deals. An objective, well-led Secretariat was absolutely crucial in this respect. It is important to stress the value of this factor. Expertise in supervision, well drafted papers and clearly set out issues provided the ideal context for the decisions reached by the Committee. The Chairman set the tone and brokered solutions between countries when difficulties arose, while ensuring that the broad goals were not lost sight of.

It is important to recall that prior to the first Capital Accord the Basle decisions were designed and adopted to meet a particular challenge at the time; and that many of these challenges arose mostly in a relatively small group of developed countries. For example, both Concordats evolved in response to the liberalisation of financial markets in many developed countries in the 1980s.

If most developing countries did not participate in the discussions it is because they were not part of the problem; and they were relatively unaffected by the results.

That changed with the 1988 Capital Accord which, although it was applicable only to the countries represented on the Basle Committee, quickly became a global standard. Partly as a result of the widespread adoption of the Accord, and partly with the rapid evolution of financial markets in many countries around the world, many more countries were affected by the decisions of the Basle Committee. It is therefore right that the machinery for arriving at these decisions takes fully into account the views of countries not represented on the Committee. I believe that is now done as a matter of standard practice, as Nick Le Pan has explained.

However, I also believe the significance of the so-called exclusion of other countries in the past may well have been exaggerated. It was my experience that after an initial period of consideration most nonBasle countries adapted the Capital Accord to suit their own situations; there was not a slavish incorporation into local regulations and nor did this result in ignoring the underlying objectives. It was rather the application of commonsense and the wholly understandable wish not to wreck their own markets and monetary arrangements that prompted the variations in capital standards; although there were the occasional window-dressers.

In any case the market kept countries and institutions honest. Egregious departures from the Accord model resulted in adverse gradings by rating agencies and higher costs. On the whole, I do not accept the arguments about neglecting the interests of smaller countries, not least because anyone who thinks 
that the regulatory authorities in Malaysia or Chile are not capable of thinking and acting for themselves, to give two examples, does not know much about the calibre of supervisors in most of the developing world.

\section{Basle, Brussels and Washington}

There is little doubt that decision taking in the form of setting standards has become more complicated in recent years. This applies both at the national and international level as agreements reached at the latter determine what is adopted at the former. The standards set in Basle have increasingly become those introduced in individual countries - with the exception of the USA in the case of the second Capital Accord, of which more later. This is scarcely surprising since one of the objectives of that agreement is to deliver equality of treatment among participants. In addition, members of the European Union are obliged to apply directives uniformly in their countries and exceptions to this practice have become rarer as the concept of super-equivalence has been abandoned.

The complications arise from two sources. First, the tensions between Brussels and Basle in arriving at a common position on the standards and, secondly, the way in which the process has been conducted in the case of the second Capital Accord.

The rivalry between Basle and Brussels is not new; nor, for that matter, is the tension between Basle and Washington. In both cases the issue is whose writ runs. But as progress in building a single European market proceeds, the various participants in the legislative process have taken an ever closer interest in the negotiations, and been subject to increasingly intense lobbying. The Commission, the Council of Ministers and the European Parliament all have their say. They are certainly disinclined to accept what Basle has agreed and, indeed, sometimes seem determined to take a different path on some issues.

The complications are exacerbated because of the fact that some EU members are not members of the Basle Committee; and some members of the Basle Committee are not members of the EU. This does not exactly make for concensus building. The US Congress questions the legitimacy of decisions reached in Basle or Brussels. Finding a way around these obstacles tests the patience of all parties and protracts the business of getting a result.

In the case of the second Capital Accord, reaching agreement has been even more challenging from the outset. The aims of the first Accord were primarily macro-prudential. Attrition of capital in internationally active banks had been going on for many years and had reached crisis proportions. It was essential to arrest this trend and stabilise the position. So the exercise was top-down in its orientation. The search for a minimum standard drove the process. The driver in the second Accord is refinement the detail of the agreement, bringing an enormous increase in complexity and putting the interests of market participants directly into the front of the discussions. These interests are bound to be varied, and have become more differentiated as products are increasingly diversified and new products have emerged.

I find it difficult to conclude that the governance of international regulation has deteriorated on the basis of Basle II alone. But let's hope it is a one-off.

\section{Structure and Resources}

It is not yet clear to me whether divesting central banks of responsibility for financial regulation and supervision results in improved financial stability, either in a single country or internationally; nor whether bringing the regulation of all financial functions and institutions within a single regulatory body 
produces this result. For one thing the international financial system has not yet been put to the test and I do not believe the supporters of an integrated financial regulator would argue that this is because that structure alone has prevented instability. There have, of course, been shocks which might in earlier times have created serious instability. That that has not happened seems to me to be attributable to other factors, such as improved risk management by financial institutions, more robust market mechanisms and instruments and greatly improved and timely financial data. The attention paid to the quality of supervision by the IMF and World Bank may well also have contributed to the absence of crises.

Above all, in my view, a period of non-inflationary growth has greatly dampened the potential for pronounced swings in asset values, a principal - if not the principal - cause of financial crises in the past.

So I have no hesitation in agreeing with the proposition that giving central banks operational independence in the area of monetary policy has been the most important structural change enhancing the stability of the financial system - that and the good fortune of having the conduct of monetary policy in the hands of an exceptional generation of central bankers.

I can also see that having a generation of well-trained and well-resourced regulators and supervisors has been a stabilising factor. The BIS and the Toronto Centre are the leaders in this specialised field of good governance. I have been fortunate to have worked with both institutions in recent years and can testify to the tangible progress being made in this area.

Nevertheless in some countries, such people and leaders are still in short supply and, typically, work in the central bank. So, in the short term, the debate about who should supervise is mostly academic. In these circumstances I believe it is mistaken to be advocating that the Central Bank lose responsibility for regulation and supervision; and that an integrated regulatory authority be established to replace the existing framework. As I have said earlier, it has yet to be demonstrated that this model delivers greater stability and efficiency in all cases. Of course, in some countries, notably in Latin America, supervision is customarily located in a separate agency or agencies, rather than in the Central Bank. In these cases my own preference is in effect the same: take care in disturbing arrangements that work fairly well. If they do not work well, the explanation is more likely to rest with the quality of people, not the prevailing structure of supervision. People matter much more than structures, especially where fashion is the driving force.

\section{Crisis Management}

There was a time when it was believed that it was not practicable to plan for crises; and that each problem was so different from every other that planning was largely futile. That is, of course, no longer the case. Regulatory authorities have established processes for reacting to failures at both the national and international levels. MOUs setting out who does what in specified circumstances are now routine. However financial crises do come in non-standard forms; and it is probably not wrong to say each is unique is some respect or degree.

Whatever the guidelines or drills that have emerged, there is therefore still a premium on agility and speed of response in tackling an emerging or actual problem that threatens the system. Deciding whether there is such a threat is itself an extremely taxing job. Then taking the right steps at the right time involves judgments which frequently have only one chance of being correct. It also involves contacting other authorities, some times across time zones, which at the very least creates the possibility of misunderstanding. 
For these reasons it is vital that supervisors, whether domestic or international, build up trust between themselves; and this can really only be done through both informal and regular contact. Hence the emphasis on mutual visits, conferences and exchanges of staff. There is a considerable esprit de corps among supervisors based on the axiom that there but for the grace of God go I. This is a powerful if somewhat intangible force, and one that cannot be scripted.

\section{Conclusion}

When I began supervising banks almost twenty-five years ago, the quality of banking supervision globally - and financial regulation and supervision generally - was significantly weaker than today. There were a relatively few countries where there was a coherent and effective system of supervision; and the amount of academic attention given to financial regulation was negligible. It was thought to be a bureaucratic backwater with only a modicum of excitement for economic students. The crises of the 1970s, 1980s and 1990s changed things radically. The costs of bank and market failure were recognised as things that need not and should not happen, at least in the same degree as before. Financial regulation and supervision became topics that attracted economists, and offered a career to bright graduates.

The Basle Committee led the way in producing principles and guidelines that addressed the main challenges facing regulators and supervisors. In the broadest sense the Committee pioneered the governance of the discipline by building a framework for taking decisions at the international level. The Committee did not attempt to impose a method of operation for supervisors, leaving the system of governance to the members in their own countries. I believe this has been a wise decision and doubt very much whether we are at a stage when the decision making process, country by country, can be homogenised with any great benefit to the financial system. The principles underlying the decision making process are well established; national variations in the detail are not only inevitable, but are probably desirable. 